\title{
Mass spectrometric imaging of elements in biological tissues by new BrainMet technique-laser microdissection inductively coupled plasma mass spectrometry (LMD-ICP-MS)
}

\author{
Bei Wu, $\dagger^{* a}$ Stefan Niehren ${ }^{b}$ and J. Sabine Becker ${ }^{a}$ \\ Received 21st March 2011, Accepted 6th July 2011 \\ DOI: 10.1039/c1ja10106d
}

\begin{abstract}
Bioimaging of elements in biological tissues is a fast growing technology in the life sciences since it provides direct information on the metal distribution which is involved in metabolism in all kinds of organisms. In the present study, we proposed a novel mass spectrometric imaging technique, laser microdissection inductively coupled plasma mass spectrometry (LMD-ICP-MS), which is intended to investigate elemental distribution in small areas of biological tissue with high spatial resolution down to the low-micrometre range and below. The LMD-ICP-MS technique combines a laser microdissection apparatus (LMD) with sensitive quadrupole-based inductively coupled plasma mass spectrometry (ICP-QMS) to utilize the tightly focused laser beam in LMD for the ablation of sample materials which then are analyzed by ICP-QMS. The laser beam with a $1 \mu \mathrm{m}$ spot diameter was used to ablate the material from a Cu-spiked brain tissue slice, and corresponding ion intensities of elements of interest (for instance, ${ }^{13} \mathrm{C}^{+}$and ${ }^{63} \mathrm{Cu}^{+}$) were observed by ICP-QMS along the scan. First images of metals and selected non-metals were obtained using the new LMD-ICP-MS imaging technique on small regions of the brain standard slice. Inhomogeneous distribution of the materials (via the image of ${ }^{13} \mathrm{C}^{+}$) and elements (via the images of ${ }^{23} \mathrm{Na}^{+},{ }^{24} \mathrm{Mg}^{+},{ }^{31} \mathrm{P}^{+},{ }^{56} \mathrm{Fe}^{+},{ }^{63} \mathrm{Cu}^{+},{ }^{64} \mathrm{Zn}^{+}$) in the scanned regions was revealed by LMD-ICP-MS imaging with a spatial resolution of $30 \mu \mathrm{m}, 15 \mu \mathrm{m}$, and $8 \mu \mathrm{m}$, respectively.

Additionally, images of $\mathrm{P}, \mathrm{Mg}, \mathrm{K}$ and $\mathrm{Fe}$ with a lateral resolution of $4 \mu \mathrm{m}$ in a region of a mouse brain slice were obtained by imaging LMD-ICP-MS. Quantification in LMD-ICP-MS was possible via calibration curves generated by a set of synthetic brain standards similar to the procedure in laser ablation ICP-MS. Further studies with respect to the performance of LMD-ICP-MS and the optimization of experimental parameters when using laser beams with smaller spot sizes in LMD will be carried out in developing the LMD-ICP-MS imaging technique.
\end{abstract}

\section{Introduction}

Trace elements are involved in a number of metabolic and physiological processes in all kinds of organisms, and their deficiency or excess may lead to different metabolic disorders, so considerable attention is being paid to the spatial distribution and local concentration of trace elements in biological tissues. In particular, the storage of metals in tissue regions and cellular organelles is considered to be one of the mechanisms for metal detoxification in both plants and animals. For instance, abnormal metal deposition indicates metabolic disorder in many diseases such as Alzheimer's, Parkinson's or Wilson's disease, ageing and ischemia. $^{1-5}$ Meanwhile, metal-containing

${ }^{a}$ Central Division of Analytical Chemistry, Forschungszentrum Jülich, D-52425 Jülich, Germany.E-mail: b.wu@fz-juelich.de; Fax: +492461 612560; Tel: +49 2461615163

${ }^{b}$ MMI Molecular Machines \& Industries AG, Flughofstrasse 37, CH-8152 Zürich, Switzerland

$\dagger$ Alexander von Humboldt postdoctoral research fellow. biomolecules have been found to be responsible for chelating the metals in those diseases. ${ }^{1,6,7}$ Therefore, bioimaging metals and molecules in such biological samples is one of the most attractive technologies applied today due to its capability of providing direct information on elemental and biomolecular distribution.

At present, bioimaging techniques are under intensive development with respect to higher spatial resolution and higher sensitivity and accuracy in order to investigate smaller areas in biological tissues or even single cells. Some of these techniques, such as matrix-assisted laser desorption/ionization mass spectrometry imaging (MALDI-MSI), nano-secondary ionization mass spectrometry (NanoSIMS), synchrotron radiation microX-ray fluorescence ( $\mu$-SRXRF), and tip-enhanced Raman spectroscopy (TERS), have achieved outstanding performance, which allows us to directly chemically image elements and molecules in the low-micrometre and nanometre range. ${ }^{8}$ However, these techniques either have difficulty in quantifying the data or require high vacuum and matrix, or are based on sophisticated facilities. In our BrainMet laboratory at 
Forschungszentrum Jülich (www.brainmet.de), near-field laser ablation inductively coupled plasma mass spectrometry (NF-LA-ICP-MS) is currently under development for the investigation of biological samples in the nanometre range. NFLA-ICP-MS is based on the physical principle of field enhancement at a metal tip which is brought into the vicinity of the sample surface in order to cause laser-induced effects such as desorption and ablation. A comprehensive illustration of the principles can be found in our previous publications. ${ }^{8,9}$ In singleshot measurements by NF-LA-ICP-MS, it is demonstrated that significantly enhanced ion intensity of the laser-ablated materials was monitored by double focusing sector field ICP-MS when the thin Ag needle tip was close to the sample surface due to the nearfield enhancement. ${ }^{9-12}$ Recently, a three-dimensional movement piezo has been introduced under the sample holder to permit imaging of samples by the novel NF-LA-ICP-MS. In addition, the system for controlling the 'tip-to-sample' distance has been adapted with a dynamic non-contact feedback mode, which makes it possible to analyze biological samples.

For elemental imaging, LA-ICP-MS has been established with the advantages of high sensitivity, low detection limits (LODs), isotopic analysis properties, easy quantification procedures and easy operation in routine work. LA-ICP-MS bioimaging has been successfully applied for studying the distribution of metals and non-metals in biological tissues, for instance, in thin sections of human and rodent brains, in plant leaves, as well as in other animal tissues, ${ }^{13}$ thereby providing fundamental information on elemental disorder in diseases in medical research and biomonitoring in the environmental sciences. The elemental distribution in rodent brain tissues can be routinely obtained in the BrainMet lab with spatial resolution from $50 \mu \mathrm{m}$ to $100 \mu \mathrm{m}$ using a commercial laser ablation system (e.g. New Wave UP266, or New Wave NWR213, Fremont, CA, USA) coupled to a sensitive ICP-MS (e.g. Agilent 7500ce, Agilent, or XSeries 2, ThermoFisher Scientific, Bremen, Germany). ${ }^{14}$ Smaller-sized laser beams are less frequently used since it would be time-consuming to analyze the whole brain slice. On the other hand, the confined laser beams may not have sufficient energy to completely ablate the material from a 20 - to 30 - $\mu \mathrm{m}$-thick tissue, resulting in lower sensitivity in ICP-MS. Recently, 5- $\mu$ m-resolution images of $\mathrm{Au}$ and $\mathrm{Ag}$ in the alveolar structures within normal human breast tissue stained by the silver-enhanced immunogold technique have been obtained using a New Wave UP213 system by Seuma et al. ${ }^{15}$ However, this achievement was based on the high concentrations of metals arising from staining, rather than those in the native tissues.

An alternative selection to a laser ablation system is to employ a laser microdissection (LMD) apparatus as the sample introduction system for a sensitive ICP-MS (LMD-ICP-MS) (Fig. 1). ${ }^{16}$ LMD, which has a tightly focused laser beam with a diameter down to $1 \mu \mathrm{m}$, was originally designed to isolate specific cells or regions of interest from microscopic regions of tissue as a sample preparation for further investigation of the isolated section. Hutchinson et al. ${ }^{17}$ combined LMD with LAICP-MS as an alternative strategy for the microanalysis of immunohistochemical sections. A laser beam with a spot size of $30 \mu \mathrm{m}$ was used to cut off Alzheimer's plaques and non-plaque materials, which were then analyzed with LA-ICP-MS to generate the images of $\mathrm{Mg}, \mathrm{Al}, \mathrm{Ca}, \mathrm{Fe}, \mathrm{Cu}$ and $\mathrm{Zn}$. However, the

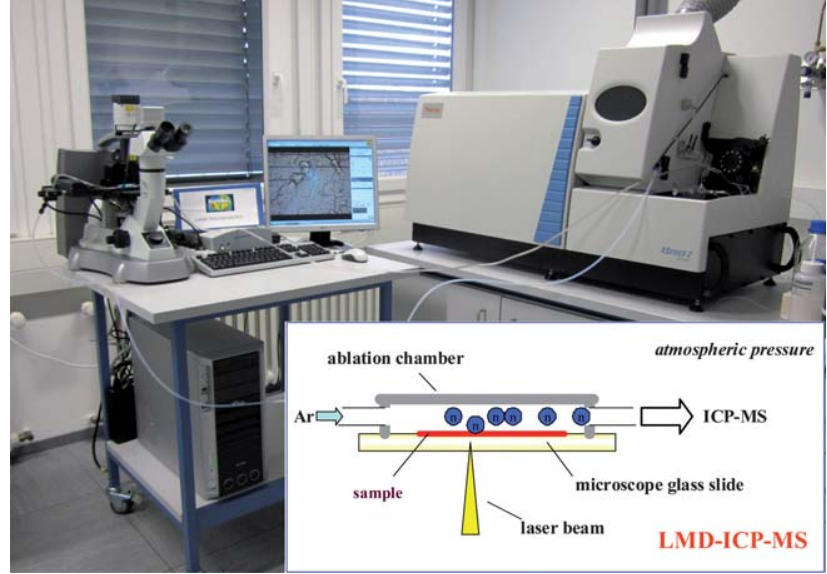

Fig. 1 Experimental setup and schematic of LMD-ICP-MS.

combination of LMD and ICP-MS enables us to take advantage of the laser beam in LMD to directly ablate the sample materials and transport the ablated materials to ICP-MS in order to obtain elemental and isotopic information within the area. ${ }^{16}$ For the first time, Becker et al. ${ }^{18}$ demonstrated the possibility of using LMD (SmartCut Plus LMD, MMI Molecular Machines and Industries, Zurich, Switzerland) as a micro-sampling system coupled with a sensitive quadrupole-based mass spectrometer with hexapole collision cell (XSeries2, ThermoFisher Scientific) for the analysis of elements in biological tissues with lateral resolution in the low- $\mu \mathrm{m}$ range. In this first test, $30-\mu \mathrm{m}$-thick brain tissue with a dried $\mathrm{Cu}$ droplet was used as the material. Laser beams from the LMD apparatus with different spot sizes (3-5 $\mu \mathrm{m})$ were applied either as line scans or in the free-hand mode (spot size $3.5 \mu \mathrm{m}$ in diameter) to ablate the material. An inhomogeneous distribution of $\mathrm{Cu}$ in the tissue was found along the scans. In addition, a precise determination of ${ }^{63} \mathrm{Cu} /{ }^{65} \mathrm{Cu}$ isotope ratios was measured by LMD-ICP-MS. However, due to the very low energy of the laser beam (about $1 \mu \mathrm{J}$ ), the ablation of the material was not complete, resulting in a high detection limit of ICP-MS.

In the ongoing study, an LMD apparatus equipped with a laser system with maximum laser energy $80 \mu \mathrm{J}$ will be applied to ablate the materials from a $30 \mu \mathrm{m}$-thick matrix-matched brain standard tissue slice in order to develop the LMD-ICP-MS technique for the analysis of biological samples. Quantitative LMD-ICP-MS imaging will also be established to study elemental distribution in brain sections with spatial resolution down to the low-micrometre level.

\section{Experimental}

\subsection{Instrumentation}

As an improvement in laser microdissection (LMD, Molecular Machines and Industries, Zurich, Switzerland) compared to that used in the previous study, ${ }^{18}$ a specified solid-state laser $(\mathrm{Nd}$ : YAG, wavelength $355 \mathrm{~nm}$ ) was integrated in the system and used to ablate the materials from a $30-\mu \mathrm{m}$-thick brain standard tissue slice and a mouse brain section with a thickness of $30 \mu \mathrm{m}$. The maximum laser energy was increased to $80 \mu \mathrm{J}$, with a repetition rate of $500 \mathrm{~Hz}$ and laser pulses of $500 \mathrm{ps}$. The laser beam can be 
tightly focused down to $1 \mu \mathrm{m}$ in the present LMD. By adjusting the laser energy and laser focus position, the diameter of the laser spot can be changed up to $30 \mu \mathrm{m}$, enabling a relatively large sample area to be scanned.

A rectangular laser ablation chamber was constructed of borosilicate glass (Duran $\AA$, Schott AG, Mainz, Germany) with inner dimensions of $27 \mathrm{~mm} \times 15 \mathrm{~mm} \times 5 \mathrm{~mm}$ for faster washout and better transport of the material to the inductively coupled plasma (ICP) compared with that used in the previous study. ${ }^{18}$ The laser ablation chamber was open at the bottom so that the microscope glass slide together with the sample directly covered the bottom without an extra sample holder.

The laser ablation chamber together with the microscopic glass slide was connected to a sensitive quadrupole-based ICP-MS with hexapole collision cell (XSeries2, Thermo Fisher Scientific, Bremen, Germany). The dwell time in the ICP-MS was set according to each element in the range of 10 to $50 \mathrm{~ms}$. The total acquisition time per data for all the isotopes measured was suitable for the consistency of the resolution of the final images and the laser spot size selected. The experimental arrangement and the schematic of LMD are given in Fig. 1.

\subsection{LMD-ICP-MS measurements}

In order to demonstrate the possibility of employing LMD-ICPMS for line scans and for imaging on biological samples, a set of matrix-matched brain standard tissues were used for ablation. The brain standard slice was prepared for routine analysis by imaging LA-ICP-MS as described in our previous publications. ${ }^{14}$ A focused laser beam with spot size of $1 \mu \mathrm{m}$ in diameter was chosen in the free-hand scanning mode to ablate a region in the brain standard spiked with $20 \mu \mathrm{g} \mathrm{g}^{-1} \mathrm{Cu}$ and $\mathrm{Fe}$ and $30 \mu \mathrm{g} \mathrm{g}^{-1} \mathrm{Zn}$ (STD1) to show the ablation of the material and corresponding signals measured by ICP-MS.

For imaging LMD-ICP-MS on the brain standard slice, laser spot sizes of $30 \mu \mathrm{m}, 15 \mu \mathrm{m}$ and $8 \mu \mathrm{m}$ were used, respectively. The scan speed was $25 \mu \mathrm{m} \mathrm{s}^{-1}$ which was the lowest velocity in the present LMD. The scanning areas were much smaller than rodent brain sections, in order to develop imaging techniques suitable for the analysis of small specific regions in the brain (for instance, hippocampal and cortical layers and amyloid plaques in
Alzheimer's disease brain) with relatively high spatial resolution. The laser ablations at $30 \mu \mathrm{m}$ and $15 \mu \mathrm{m}$ spot sizes were carried out in the areas containing two parts: to the left was the standard tissue of STD1, and to the right was the tissue without spikes (STD0). For the laser ablation with a laser beam of spot size 8 $\mu \mathrm{m}$, a region in STD1 was scanned to ensure sufficient sensitivity in ICP-MS.

A region with different layers (cortex, corpus callosum, striatum and pericallosal blood vessels) in a mouse brain slice with a thickness of $30 \mu \mathrm{m}$ was chosen to show elemental distribution with spatial resolution of $4 \mu \mathrm{m}$. The mouse brain was embedded in paraffin before cryo-sectioning. Since the present scan speed of $25 \mu \mathrm{m} \mathrm{s}^{-1}$ was relatively fast, only a few elements (C, P, S, Mg, K, $\mathrm{Fe}$ and $\mathrm{Cu}$ ) were monitored with a dwell time of $10 \mathrm{~ms}$ for each isotope to ensure enough data were acquired for high resolution of the images. The parameters used in LMD-ICP-MS measurements are summarized in Table 1.

In order to establish possible quantification methods for imaging LMD-ICP-MS, the brain standard slice was line-scanned using laser beams with different spot sizes of $30 \mu \mathrm{m}, 15 \mu \mathrm{m}, 8$ $\mu \mathrm{m}$, and $4 \mu \mathrm{m}$, respectively. Five line scans were carried out for each standard with the selected laser beam. The intensities obtained by ICP-MS in each line scan were averaged and plotted with the spiked concentration to generate calibration curves for quantification purposes.

\section{Results and discussion}

\subsection{Line scan on brain standard tissues by LMD-ICP-MS}

In the previous study we demonstrated an inhomogeneous $\mathrm{Cu}$ distribution along a free-hand scan using a laser beam with spot size of $3.5 \mu \mathrm{m}$ in LMD and along line scans at $3 \mu \mathrm{m}$ and $5 \mu \mathrm{m}$, respectively. ${ }^{18}$ However, the material from the $30-\mu \mathrm{m}$-thick brain tissue was not completely ablated due to the low laser energy of 1 $\mu \mathrm{J}$ applied in these experiments. In the present study, the maximum laser energy was increased to $80 \mu \mathrm{J}$, which was possibly sufficient for a full ablation of such a brain tissue of 30 $\mu \mathrm{m}$ thickness. In the present LMD apparatus, different spot sizes of the laser beams were achieved by changing the laser energy output and the laser focus position. In general, increasing the laser energy in LMD resulted in a laser beam with a larger spot

Table 1 Operation parameters in LMD-ICP-MS measurements on brain standard tissue slice and mouse brain slice

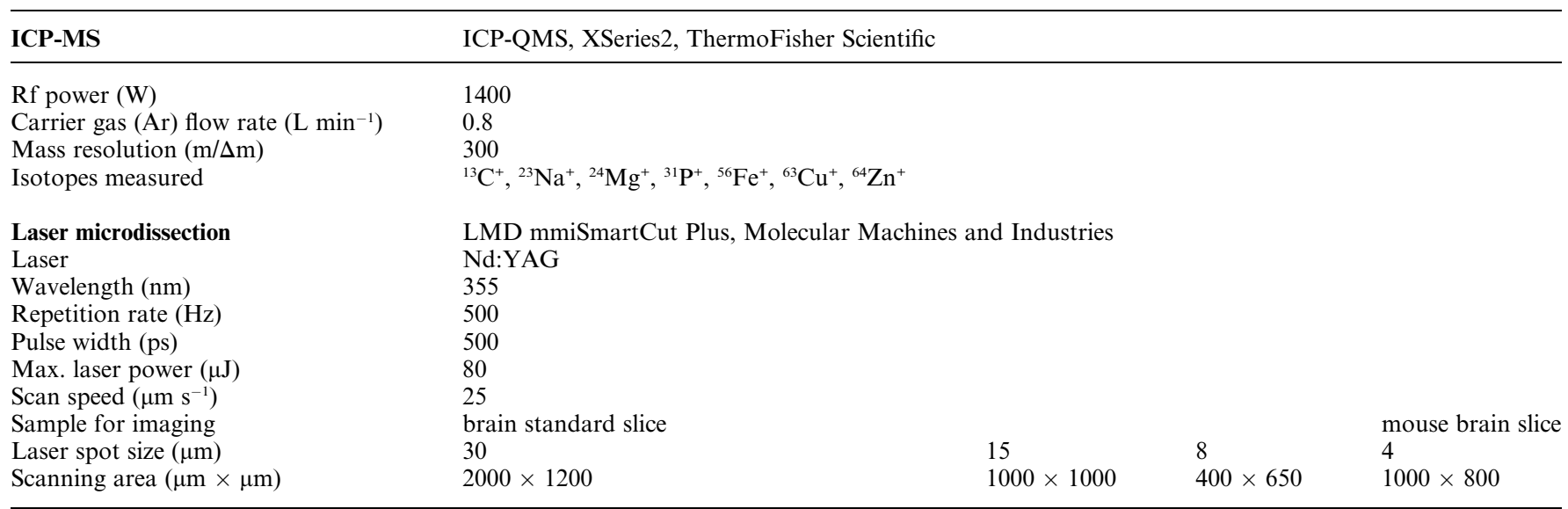


size. The laser focus position was adjusted accordingly in order to avoid the ablation of the glass substrate. In the present study, the maximum laser energy with appropriate laser focus position produced a laser beam with a spot size of $30 \mu \mathrm{m}$. However, decreasing the laser energy to achieve smaller laser spot sizes down to $1 \mu \mathrm{m}$ may challenge the full ablation of the materials from the $30-\mu \mathrm{m}$-thick tissue slice.

Fig. 2 shows a region in the brain standard slice before and after ablation by $1-\mu \mathrm{m}$-wide free-hand line scan in LMD and corresponding ion intensities of ${ }^{13} \mathrm{C}^{+}$and ${ }^{63} \mathrm{Cu}^{+}$analyzed by ICPMS. From the optical microscopic view, this region had a darker edge due to the folding and agglomeration of the materials during sample preparation. In fact, it was observed that, after ablation, the material in the darker edge was not completely ablated, while that in the lighter part showed a clean ablation with a line width of $1 \mu \mathrm{m}$ (Fig. 2A,B). This can be explained by the fact that the effective energy on the sample at $1 \mu \mathrm{m}$ spot size was $36.6 \mu \mathrm{J}$, which was not sufficient to ablate the material with high density and thickness. The same free-hand scan was then run again in the same region. The second scan allowed the material to be completely ablated, as shown in Fig. 2C. Whereas the part that was completely ablated in the first run resulted in a greater width of the ablated line, indicating that the material adjacent to the set scan was also ablated. The inhomogeneity of the material along the scan can be clearly seen by the change in ${ }^{13} \mathrm{C}^{+}$intensities in both of the two runs (Fig. 2D). ${ }^{63} \mathrm{Cu}^{+}$was also

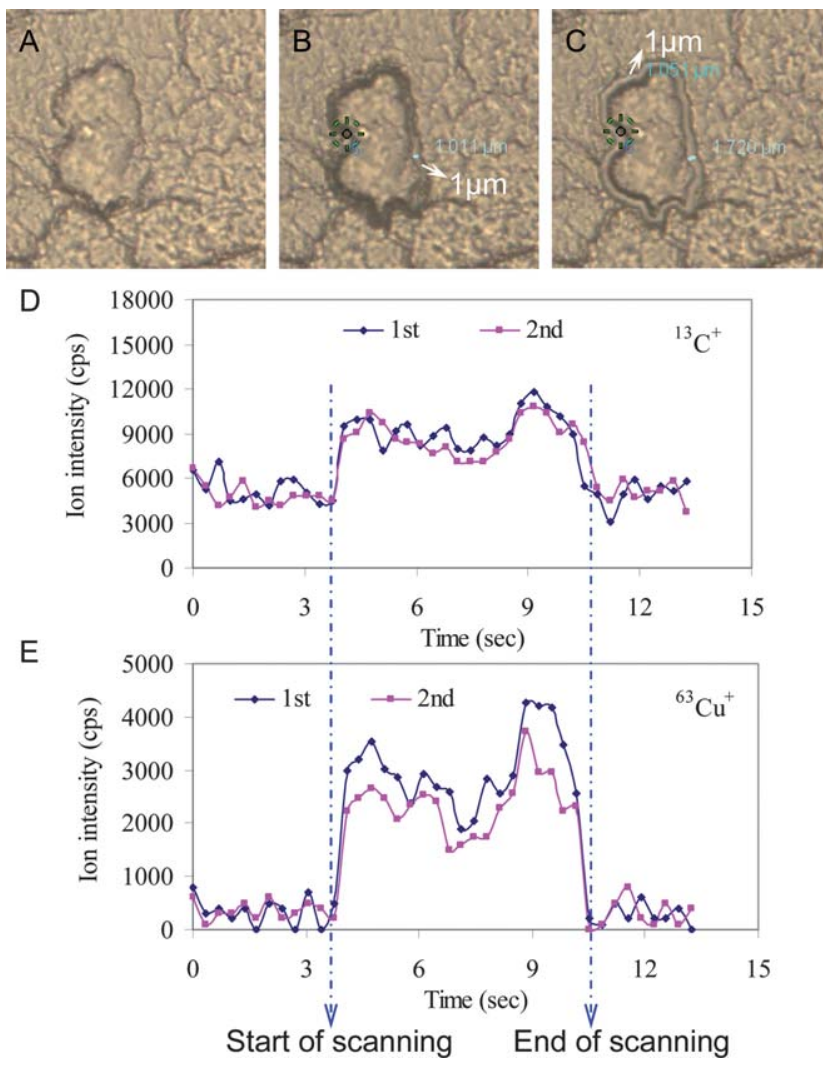

Fig. 2 LMD-ICP-MS analysis on brain standard slice using laser beam with $1 \mu \mathrm{m}$ spot size in free-hand mode (A: before ablation; B: after 1st ablation; C: after 2nd ablation; D: ion intensity of ${ }^{13} \mathrm{C}^{+}$in two scans; $\mathrm{E}$ : ion intensity of ${ }^{63} \mathrm{Cu}^{+}$in two scans). monitored and showed inhomogeneous distribution in the scans (Fig. 2E) similar to that of ${ }^{13} \mathrm{C}^{+}$. The signals of ${ }^{13} \mathrm{C}^{+}$and ${ }^{63} \mathrm{Cu}^{+}$in the material were significantly higher than those of the gas background, which allowed sufficient sensitivity for LMD-ICPMS measurements on biological tissues on the low-micrometre scale.

\subsection{Imaging of elements in brain standard tissues by LMD- ICP-MS}

In order to apply the new LMD-ICP-MS to the imaging of elements in brain tissues, we chose a brain standard tissue slice as the sample to study the figure of merit of imaging LMD-ICPMS. Although there was no biological structure in the brain standard slice, inhomogeneous distribution of the tissue materials could be observed in the optical microscopic pictures (Fig. 3a,b,c), where the dark regions (e.g. regions shown by a crimson arrow) indicated more material and the light-colored regions showed a thinner layer of the material, as well as the 'holes' (e.g. regions shown by a blue-colored arrow), which had been bubbles before cryo-sectioning, that had formed during sample preparation procedures. In the optical microscopic pictures, the boundary (the purple lines in Fig. 3a,b) of two standard tissues (STD1 and STD0) can be identified in the scanning areas, where the left-hand part contained higher element concentrations than the right-hand part.

In the present study, a relatively fast scan speed $\left(25 \mu \mathrm{m} \mathrm{s}^{-1}\right)$ was used due to the original purpose of the LMD apparatus which was for precise and fast cutting of regions of interest. Therefore, the spatial resolution was limited to $8 \mu \mathrm{m}$ when up to 20 isotopes of interest were to be measured, with further consideration of the dwell time necessary for analyzing each isotope. However, we are upgrading the LMD apparatus and the software to obtain a much slower scan speed down to $2.5 \mu \mathrm{m} \mathrm{s}^{-1}$, which is expected to be sufficiently efficient for analysis of at least 20 isotopes with appropriate dwell times in order to reach higher lateral resolution.

Notwithstanding, we demonstrated for the first time the imaging of metals and non-metals using the new LMD-ICP-MS configuration with spatial resolution below $10 \mu \mathrm{m}$. The optical pictures of the scanning areas and LMD-ICP-MS images of elements in these areas with spatial resolutions of $30 \mu \mathrm{m}, 15 \mu \mathrm{m}$, and $8 \mu \mathrm{m}$ are shown in Fig. 3A, B, and C, respectively. All the images of elements measured by LMD-ICP-MS with different lateral resolutions revealed an inhomogeneous distribution of the materials and elements in the scanning area. For instance, much more $\mathrm{P}$ was detected in the tissue region than in the region where the holes were present, because there was significantly higher $\mathrm{P}$ concentration in the biological tissues than in the background. In the tissue region, however, the materials were not ideally homogenized, and there were differences in tissue thickness and density. As indicated in the images of ${ }^{13} \mathrm{C}^{+}$, the uniformity of the materials was quite low and the ion intensity of ${ }^{13} \mathrm{C}^{+}$varied between 0.7 - to 1.3 -fold of the mean value. This is attributed to the sample preparation procedures when the standard solution containing high concentrations of metals was added to the tissues; the acidity of the solution, which was intended to prevent metals from precipitating, caused degradation and agglomeration of the tissue materials. Our results show the importance of 


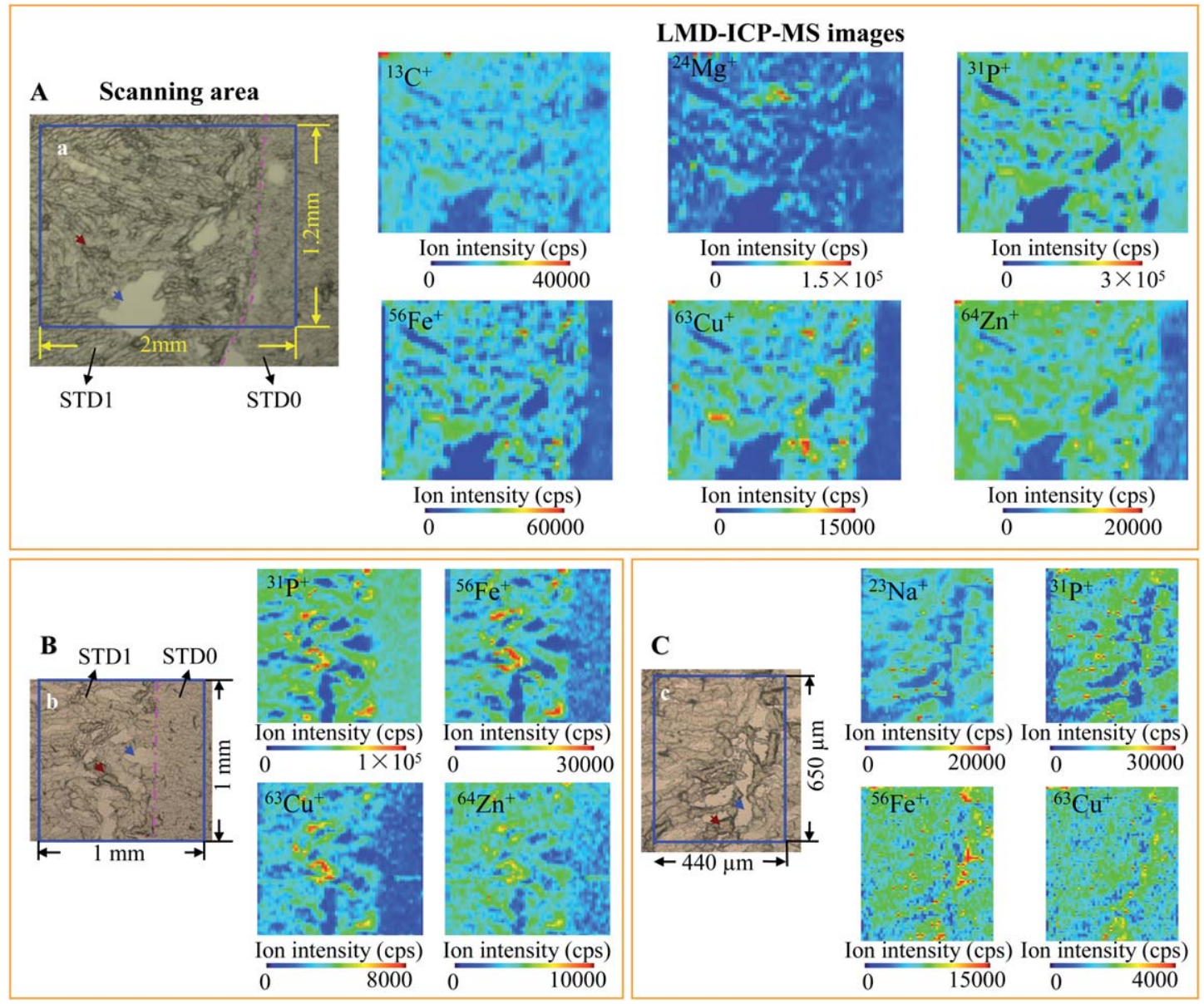

Fig. 3 LMD-ICP-MS imaging of metals and selected non-metals in a brain standard slice with spatial resolution of $30 \mu \mathrm{m}$ (A), $15 \mu \mathrm{m}$ (B), and $8 \mu \mathrm{m}$ (C). ( $\mathrm{a}, \mathrm{b}$, and $\mathrm{c}$ show the optical microscopic views of the scanning area; crimson arrows indicate the region with high material density, while the blue arrows point to the hollow holes present in the material formed during sample preparation; in A and B, to the left of the purple line is shown the tissue spiked with $20 \mu \mathrm{g} \mathrm{g}^{-1} \mathrm{Cu}$ and $\mathrm{Fe}$ and $30 \mu \mathrm{g} \mathrm{g}^{-1} \mathrm{Zn}$ (STD1), while the right-hand part is without spikes (STD0)).

an appropriate standard synthesis procedure for quantification purposes in mass spectrometric imaging of biological tissues. Therefore, we are now developing a brand-new preparation method for matrix-matched biological standards with high homogeneity and coherence.

Note that in the images with a resolution of 30 and $15 \mu \mathrm{m}$ the concentrations of $\mathrm{Fe}, \mathrm{Cu}$ and $\mathrm{Zn}$ in the left-hand and the righthand part of the scanning areas also appear to be remarkably different due to the spiked tissue in the left-hand part (STD1). $\mathrm{Mg}$ and $\mathrm{P}$ also exhibited relatively higher intensities in the lefthand part, although these two elements had not been added in the spikes. We explained this by the fact that more materials were ablated which could be clearly revealed by ${ }^{13} \mathrm{C}^{+}$images. The images of elements ( $\mathrm{Na}, \mathrm{P}, \mathrm{Fe}$, and $\mathrm{Cu}$ in Fig. 3C) with a resolution of $8 \mu \mathrm{m}$ suggested an inhomogeneous distribution of materials and elements in the scanning area as well, although the quality of the images was not as good as that at $30-$ and $15-\mu \mathrm{m}$ resolution. One of the reasons could be that with a smaller laser spot, less material was ablated resulting in lower ion intensities measured by ICP-MS. The mean ion intensities for ${ }^{56} \mathrm{Fe}^{+}$and ${ }^{63} \mathrm{Cu}^{+}$in the region were around $10000 \mathrm{cps}$ and $3000 \mathrm{cps}$, respectively, which were about one third of those when using a 30 $\mu \mathrm{m}$ spot-sized laser beam, respectively. Nevertheless, the experimental arrangement and operation parameters in LMDICP-MS should be further optimized in order to improve the performance of LMD-ICP-MS imaging with higher spatial resolution.

\subsection{Imaging of elements in brain tissue by LMD-ICP-MS}

In order to study the elemental distribution in small specific regions of a brain tissue with high spatial resolution, the novel LMD-ICP-MS imaging technique was used to investigate a region in a $30-\mu \mathrm{m}$-thick brain section with multiple layers, including cortex, corpus callosum, striatum and pericallosal blood vessels. The spot size of the laser beam in LMD was adjusted to $4 \mu \mathrm{m}$ to achieve high spatial resolution. In the present study, only 6 elements (11 isotopes, ${ }^{13} \mathrm{C}^{+},{ }^{24} \mathrm{Mg}^{+},{ }^{25} \mathrm{Mg}^{+},{ }^{31} \mathrm{P}^{+}$, ${ }^{39} \mathrm{~K}^{+},{ }^{56} \mathrm{Fe}^{+},{ }^{57} \mathrm{Fe}^{+},{ }^{63} \mathrm{Cu}^{+}$and ${ }^{63} \mathrm{Cu}^{+}$) were monitored due to the fast scan speed.

Images of ${ }^{24} \mathrm{Mg}^{+},{ }^{31} \mathrm{P}^{+},{ }^{39} \mathrm{~K}^{+}$and ${ }^{56} \mathrm{Fe}^{+}$clearly presented the four layers in the region, while images of other isotopes (for instance, ${ }^{13} \mathrm{C}^{+}$and ${ }^{63} \mathrm{Cu}^{+}$) did not show the structures due to the low ion intensities measured by ICP-MS using such a small-sized laser beam (Fig. 4). High concentrated Fe in the area $d$ indicated the location of the pericallosal blood vessels, while lowest Fe levels 


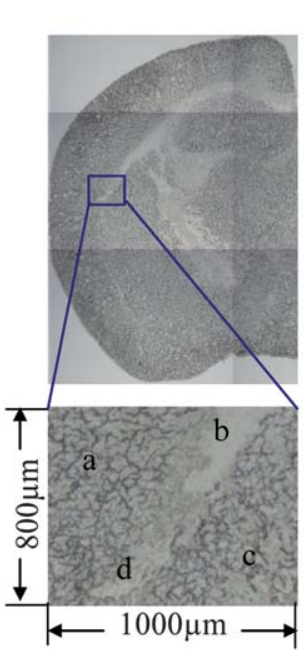

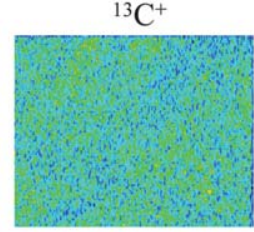
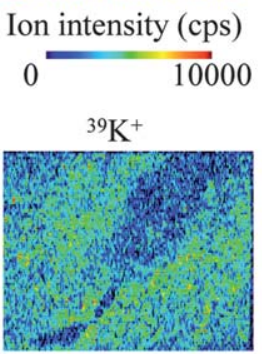

Ion intensity (cps)

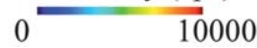

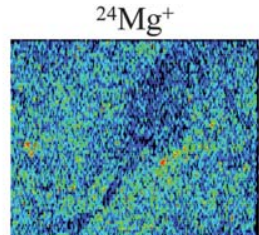

Ion intensity (cps)
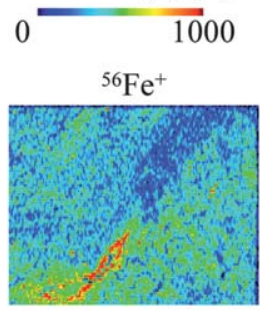

Ion intensity (cps)

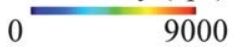

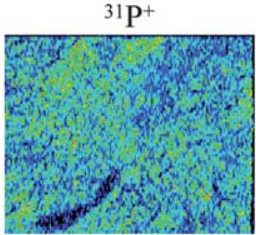

Ion intensity (cps)
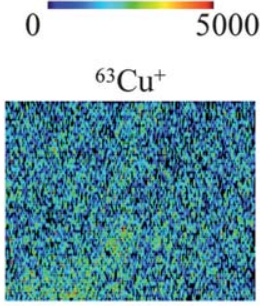

Ion intensity (cps)

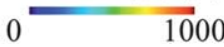

Fig. 4 LMD-ICP-MS imaging of $\mathrm{C}, \mathrm{Mg}, \mathrm{P}, \mathrm{K}, \mathrm{Fe}$, and $\mathrm{Cu}$ in a region (bottom left) of a brain slice (top left) with the spatial resolution of $4 \mu \mathrm{m}$. (a, cortex; $b$, corpus callosum; $c$, striatum, and $d$, pericallosal blood vessels).

were found in the layer of corpus callosum, which was consistent with the Fe image revealed by imaging LA-ICP-MS. ${ }^{13}$ It was observed that $\mathrm{P}$ and $\mathrm{C}$ were less abundant in the corpus callosum than in the cortex, which was different from the distribution of $\mathrm{P}$ and $\mathrm{C}$ in native brains. ${ }^{19}$ In our previous study of elemental distribution in native mouse brain, $\mathrm{P}$ and $\mathrm{C}$ were highly elevated in white matter (corpus callosum, fornix, capsula interna, commissural anterior, and so on) corresponding to higher concentrations of lipids and lower water content compared with that in gray matter (for instance, the cortex) ${ }^{19}$ Paraffin embedding caused a dehydration effect, resulting in redistribution of the elements. If the tissue was cut in the native state, and then dehydrated and paraffin embedded, higher $\mathrm{C}$ and $\mathrm{P}$ in the white matter would be preserved. ${ }^{20}$

\subsection{Possible quantification method used in LMD-ICP-MS}

In the present study, the brain standard slice used for quantification purposes in routine LA-ICP-MS imaging of brain tissues in our lab $\mathrm{b}^{14}$ was applied to develop the quantification method in LMD-ICP-MS. The set of brain standards were line-scanned by the focused laser beam in LMD with a spot size of $30 \mu \mathrm{m}, 15 \mu \mathrm{m}$, $8 \mu \mathrm{m}$ and $4 \mu \mathrm{m}$, respectively, in the same experimental conditions as those used when LMD-ICP-MS imaging measurements were carried out. Table 2 summarizes the calibration curves for $\mathrm{Fe}, \mathrm{Cu}$ and $\mathrm{Zn}$, and corresponding regression coefficients $\left(R^{2}\right)$ obtained by LMD-ICP-MS. High linear correlation coefficients of the calibration curves $\left(R^{2}>0.95\right)$ were achieved and were comparable with the $R^{2}$ obtained in our routine LA-ICP-MS measurements. ${ }^{14}$ The concentration values extrapolated by the calibration curves agreed with the values in the standards measured by ICP-MS after microwave digestion (data not shown). In addition, the limits of detection (LODs) of each element obtained when using laser beams with different spot sizes were within biologically relevant ranges and were acceptable for the analysis of biological samples (Table 2). Therefore, those calibration curves and the quantification procedures used in LAICP-MS could be applied to quantify the data from LMD-ICP-
Table 2 Calibration curves and limits of detection in LMD-ICP-MS with lateral resolution of $30 \mu \mathrm{m}, 15 \mu \mathrm{m}, 8 \mu \mathrm{m}$, and $4 \mu \mathrm{m}$, obtained from a $30-\mu \mathrm{m}$-thick synthetic brain standard section

\begin{tabular}{lllll}
\hline $\begin{array}{l}\text { Laser spot } \\
\text { size }(\mu \mathrm{m})\end{array}$ & Element & Calibration curve & $R^{2}$ & $\begin{array}{l}\text { LODs } \\
\left(\mu \mathrm{g} \mathrm{g}^{-1}\right)\end{array}$ \\
\hline 30 & $\mathrm{Fe}$ & $y=985.32 x+28510$ & 0.9554 & 0.4 \\
& $\mathrm{Cu}$ & $y=365.89 x+2449.3$ & 0.9872 & 1.1 \\
& $\mathrm{Zn}$ & $y=277.72 x+4658.1$ & 0.9700 & 1.3 \\
15 & $\mathrm{Fe}$ & $y=616.31 x+16405$ & 0.9587 & 1.9 \\
& $\mathrm{Cu}$ & $y=223.46 x+1322.2$ & 0.9860 & 2.7 \\
& $\mathrm{Zn}$ & $y=171.24 x+2710.9$ & 0.9737 & 3.3 \\
8 & $\mathrm{Fe}$ & $y=356.08 x+9132.7$ & 0.9641 & 3.9 \\
& $\mathrm{Cu}$ & $y=181.21 x+970.83$ & 0.9634 & 4.6 \\
4 & $\mathrm{Zn}$ & $y=57.954 x+982.59$ & 0.9797 & 13.4 \\
& $\mathrm{Fe}$ & $y=127.04 x+2906.6$ & 0.9786 & 8.0 \\
& $\mathrm{Cu}$ & $y=33.585 x+194.533$ & 0.9598 & 11.3 \\
& $\mathrm{Zn}$ & $y=34.278 x+536.87$ & 0.9901 & 18.2 \\
\hline
\end{tabular}

MS measurements. The concentrations of $\mathrm{Fe}, \mathrm{Cu}$ and $\mathrm{Zn}$ in the spiked standard in the scanned area in Fig. 3 varied in the ranges of 53-74 $\mu \mathrm{g} \mathrm{g}^{-1}, 30-37 \mu \mathrm{g} \mathrm{g}^{-1}, 49-59 \mu \mathrm{g} \mathrm{g}^{-1}$, respectively, while in the brain section up to $40 \mu \mathrm{g} \mathrm{g}^{-1} \mathrm{Fe}$ was observed in the blood vessels (Fig. 4). In further studies, other quantification strategies, such as using on-line solution-based calibration, ${ }^{21,22}$ are planned to be applied in LMD-ICP-MS analysis.

\section{Conclusion}

In the present study, we demonstrated an instrumentation improvement by combining a LMD apparatus with an ICPQMS, and showed the possibility to image metals and nonmetals in biological tissues by the novel LMD-ICP-MS with high spatial resolution down to the low-micrometre level. Compared with the previous study, ${ }^{18}$ the ablation of the material in a $30-\mu \mathrm{m}$ thick brain standard tissue was more efficient and a high ion intensity of elements was monitored in ICP-MS. For the first time, imaging of a biological tissue was achieved with spatial resolution of $30 \mu \mathrm{m}, 15 \mu \mathrm{m}$ and $8 \mu \mathrm{m}$, respectively, by the novel 
LMD-ICP-MS imaging technique. Moreover, images of $\mathrm{Mg}, \mathrm{K}$ $\mathrm{Fe}$ and $\mathrm{P}$ with a lateral resolution of $4 \mu \mathrm{m}$ was achieved in a small region of a mouse brain section by imaging LMD-ICP-MS. Quantitative LMD-ICP-MS was developed by using the quantification procedures applied in routine LA-ICP-MS imaging via calibration curves from the matrix-matched brain standards. The low LODs in LMD-ICP-MS were within biologically relevant ranges and were acceptable for the analysis of biological samples.

At present, the spatial resolution of $4 \mu \mathrm{m}$ was achieved by the proposed LMD-ICP-MS imaging technique, yet is not sufficient for our goal to investigate single cells. The laser beam in the LMD can be focused down to $1 \mu \mathrm{m}$ and below in spot size, however, in return it requires high sensitivity of a mass spectrometer for the analysis of a native biological tissue without spikes. Therefore, in the following studies, the LMD apparatus will be coupled to a sector field ICP-MS which is at least ten times more sensitive than the quadrupole-based ICP-MS. On the other hand, the LMD itself needs to be updated regarding fine control of the scanning stage and lower scan speed. Furthermore, a series of studies are planned as part of the future development to improve the performance of the technique, including the investigation of the laser ablation process in the LMD, and new designs of laser ablation cells to increase ablation efficiency and transport of the materials. For quantification purposes, the procedure using prepared matrix-matched standards can be applied in LMD-ICP-MS measurements, as shown in the present study and in routine LA-ICP-MS analysis. However, the homogeneity of the standards has to be well-considered when applying a micro-local analysis. The technique of on-line solution-based quantification would be a good strategy to quantify the LMD-ICP-MS images. LMD-ICP-MS imaging will soon allow us to chemically image small tissues and cellular substructures with high spatial resolution.

\section{Acknowledgements}

The first author gratefully acknowledges financial support for this work from the Alexander von Humboldt Foundation. We are extremely grateful to Prof. Dr N. J. Shah (Institute of Neurosciences and Medicine: Medical Imaging Physics (INM-4) Forschungszentrum Jülich) and Dr Antje Plaschke-Schluetter (Molecular Machines and Industries, Zurich, Switzerland) for their generous support for this work. The authors would especially like to thank Dr Andreas Matusch (Institute of Neurosciences and Medicine: Molecular Organization of the Human Cortex (INM-2), Forschungszentrum Jülich) for preparing the brain standard slice and the discussion of the results. Special thanks are given to Mrs. J. Carter-Sigglow (Language Services, Central Library, Forschungszentrum Jülich) for revising the English text.

\section{References}

1 K. Jomova, D. Vondrakova, M. Lawson and M. Valko, Mol. Cell. Biochem., 2010, 345, 91-104.

2 L. M. Miller, Q. Wang, T. P. Telivala, R. J. Smith, A. Lanzirotti and J. Miklossy, J. Struct. Biol., 2006, 155, 30-37.

3 B. F. Gh Popescu, M. J. George, U. Bergmann, A. V. Garachtchenko, M. E. Kelly, R. P. E. McCrea1, K. Lüning, R. M. Devon, G. N. George, A. D. Hanson, S. M. Harder, L. D. Chapman, I. J. Pickering and H. Nichol, Phys. Med. Biol., 2009, 54, 651-663.

4 H. J. Wang, M. Wang, B. Wang, X. Y. Meng, Y. Wang, M. Li, W. Y. Feng, Y. L. Zhao and Z. F. Chai, J. Anal. At. Spectrom., 2010, 25, 328-333.

5 A. C. Leskovjan, A. Lanzirotti and L. M. Miller, NeuroImage, 2009, 47, 1215-1220.

6 N. G. Nair, G. Perry, M. A. Smith and V. P. Reddy, J. Alzheimers Dis., 2010, 20, 57-66.

7 P. Faller, ChemBioChem, 2009, 10, 2837-2845.

8 B. Wu and J. S. Becker, Int. J. Mass Spectrom., 2011, DOI: 10.1016/j. ijms.2011.01.019.

9 J. S. Becker, A. Gorbunoff, M. Zoriy, A. Izmer and M. Kayser, J. Anal. At. Spectrom., 2006, 21, 19-25.

10 M. V. Zoriy, M. Kayser and J. S. Becker, Int. J. Mass Spectrom., 2008, 273, 151-155.

11 M. V. Zoriy and J. S. Becker, Rapid Commun. Mass Spectrom., 2009, 23, 23-30.

12 M. V. Zoriy, D. Mayer and J. S. Becker, J. Am. Soc. Mass Spectrom., 2009, 20, 883-890.

13 J. S. Becker, M. Zoriy, A. Matusch, B. Wu, D. Salber, J. C. Palm and J. Su. Becker, Mass Spectrom. Rev., 2010, 29, 156-175.

14 J. S. Becker, A. Matusch, J. Su. Becker, B. Wu, C. Palm, A. J. Becker and D. Salber, Int. J. Mass Spectrom., 2011, DOI: 10.1016/j. ijms.2011.01.015.

15 J. Seuma, J. Bunch, A. Cox, C. McLeod, J. Bell and C. Murray, Proteomics, 2008, 8, 3775-3784.

16 J. S. Becker and D. Salber, Patent (8.4.2009) WO2010115394 A1 granted Dec. 2010.

17 R. W. Hutchinson, A. G. Cox, C. W. McLeod, P. S. Marshall, A. Harper, E. L. Dawson and D. R. Howlett, Anal. Biochem., 2005, 346, 225-233.

18 J. S. Becker, S. Niehren, A. Matusch, B. Wu, H.-F. Hsieh, U. Kumtabtim, M. Hamester, A. Plaschke-Schlütter and D. Salber, Int. J. Mass Spectrom., 2010, 294, 1-6.

19 J. S. Becker, M. Zoriy, B. Wu, A. Matusch and J. Su. Becker, J. Anal. At. Spectrom., 2008, 23, 1275-1280.

20 A. Matusch, A. Bauer and J. S. Becker, Int. J. Mass Spectrom., 2011, DOI: 10.1016/j.jims.2011.03.006.

21 V. L. Dressler, D. Pozebon, M. F. Mesko, A. Matusch, U. Kumtabtim, B. Wu and J. S. Becker, Talanta, 2010, 82, 1770-1777.

22 D. Pozebon, V. L. Dressler, M. F. Mesko, A. Matusch and J. S. Becker, J. Anal. At. Spectrom., 2010, 25, 1739-1744. 